\title{
Comparison of different real time VOC measurement techniques in a ponderosa pine forest
}

\author{
L. Kaser $^{1}$, T. Karl ${ }^{2}$, R. Schnitzhofer ${ }^{1}$, M. Graus ${ }^{3,4}$, I. S. Herdlinger-Blatt ${ }^{1}$, J. P. DiGangi ${ }^{5, *}$, B. Sive ${ }^{6,7}$, A. Turnipseed ${ }^{2}$, \\ R. S. Hornbrook ${ }^{2}$, W. Zheng ${ }^{2}$, F. M. Flocke ${ }^{2}$, A. Guenther ${ }^{2}$, F. N. Keutsch ${ }^{5}$, E. Apel ${ }^{2}$, and A. Hansel ${ }^{1}$ \\ ${ }^{1}$ Institute of Ion Physics and Applied Physics, University of Innsbruck, Innsbruck, Austria \\ ${ }^{2}$ Atmospheric Chemistry Division, National Center for Atmospheric Research, Boulder, CO, USA \\ ${ }^{3}$ Chemical Sciences Division, NOAA Earth System Research Laboratory, Boulder, CO, USA \\ ${ }^{4}$ Cooperative Institute for Research in Environmental Sciences (CIRES), University of Colorado, Boulder, CO, USA \\ ${ }^{5}$ Department of Chemistry, University of Wisconsin-Madison, Madison, WI, USA \\ ${ }^{6}$ Department of Chemistry, Appalachian State University, Boone, NC, USA \\ ${ }^{7}$ Environmental Science Program, Appalachian State University, Boone, NC, USA \\ * now at: Civil \& Environmental Engineering, Princeton University, Princeton, NJ, USA
}

Correspondence to: A. Hansel (armin.hansel@uibk.ac.at)

Received: 17 August 2012 - Published in Atmos. Chem. Phys. Discuss.: 24 October 2012

Revised: 20 February 2013 - Accepted: 21 February 2013 - Published: 11 March 2013

\begin{abstract}
Volatile organic compound (VOC) mixing ratios measured by five independent instruments are compared at a forested site dominated by ponderosa pine (Pinus Ponderosa) during the BEACHON-ROCS field study in summer 2010. The instruments included a Proton Transfer Reaction Time of Flight Mass Spectrometer (PTR-TOF-MS), a Proton Transfer Reaction Quadrupole Mass Spectrometer (PTR-MS), a Fast Online Gas-Chromatograph coupled to a Mass Spectrometer (GC/MS; TOGA), a Thermal Dissociation Chemical Ionization Mass Spectrometer (PAN-CIMS) and a Fiber Laser-Induced Fluorescence Instrument (FILIF). The species discussed in this comparison include the most important biogenic VOCs and a selected suite of oxygenated VOCs that are thought to dominate the VOC reactivity at this particular site as well as typical anthropogenic VOCs that showed low mixing ratios at this site. Good agreement was observed for methanol, the sum of the oxygenated hemiterpene 2methyl-3-buten-2-ol (MBO) and the hemiterpene isoprene, acetaldehyde, the sum of acetone and propanal, benzene and the sum of methyl ethyl ketone (MEK) and butanal. Measurements of the above VOCs conducted by different instruments agree within $20 \%$. The ability to differentiate the presence of toluene and cymene by PTR-TOF-MS is tested based on a comparison with GC-MS measurements, suggesting a study-average relative contribution of $74 \%$ for toluene and
\end{abstract}

$26 \%$ for cymene. Similarly, 2-hydroxy-2-methylpropanal (HMPR) is found to interfere with the sum of methyl vinyl ketone and methacrolein (MVK + MAC) using PTR-(TOF)$\mathrm{MS}$ at this site. A study-average relative contribution of $85 \%$ for MVK + MAC and $15 \%$ for HMPR was determined. The sum of monoterpenes measured by PTR-MS and PTR-TOFMS was generally 20-25\% higher than the sum of speciated monoterpenes measured by TOGA, which included $\alpha$ pinene, $\beta$-pinene, camphene, carene, myrcene, limonene, cineole as well as other terpenes. However, this difference is consistent throughout the study, and likely points to an offset in calibration, rather than a difference in the ability to measure the sum of terpenes. The contribution of isoprene relative to MBO inferred from PTR-MS and PTR-TOF-MS was smaller than $12 \%$ while GC-MS data suggested an average of $21 \%$ of isoprene relative to MBO. This comparison demonstrates that the current capability of VOC measurements to account for $\mathrm{OH}$ reactivity associated with the measured VOCs is within $20 \%$.

\section{Introduction}

The oxidation of volatile organic compounds (VOCs) plays a central role in atmospheric chemistry by fueling ozone 
chemistry (Atkinson, 2000) and generating organic aerosols (Hallquist et al., 2009). Uncertainties regarding emission potentials and oxidation mechanisms associated with biogenic sources have been identified in previous studies (Di Carlo et al., 2004; Goldstein et al., 2004). The Bio-hydro-atmosphere interactions of Energy, Aerosols, Carbon, $\mathrm{H}_{2} \mathrm{O}$, Organics \& Nitrogen (BEACHON)-Rocky Mountain Organic Carbon Study (ROCS) was conducted to achieve a better understanding of the exchange of biogenic VOCs and their influence on the oxidative capacity of the atmosphere.

A variety of instruments for measuring VOCs in the atmosphere exist; all of them having advantages and disadvantages. For example, instruments based on gas chromatography have the potential to analyze and quantify a large variety of molecules concurrently, with high sensitivity and specificity. However, some chromatographic techniques can be subject to sampling artifacts during pre-concentration of the sampled air. As well, chromatographic methods generally have a relatively low time resolution. Spectroscopic techniques can achieve high time resolution and low limits of detection but are specific to one or few molecules per instrument. Chemical ionization techniques can achieve high time resolution but difficulties can arise in the identification and separation of some molecular species. Some of these disadvantages can be improved by using higher-resolution mass analyzers, for example time of flight mass spectrometers, but even with these advanced instruments, isomers can remain unresolved and ionic fragments of species cannot be unambiguously assigned to their parent compounds.

An important prerequisite for understanding gas-phase chemistry of VOCs is the ability to quantitatively measure the relevant VOCs. Comparing co-located measurement techniques can be a highly useful method for evaluating different measurement systems and assessing the uncertainty in the measurements. Several comparison studies were conducted in the last decade ranging from measurements at highly anthropogenic influenced sites (Kuster et al. 2004; Fortner et al., 2009) to highly controlled environments such as a laboratory chamber (Apel et al., 2008) or airborne (Kleb et al., 2011) intercomparisons.

During BEACHON-ROCS the presence of a suite of complementary gas-phase instrumentation allowed a rigorous comparison of several measurement techniques in a realworld forest environment. The real-time VOC measurement instruments consisted of a Proton Transfer Reaction Time of Flight Mass Spectrometer (PTR-TOF-MS) based on a recently developed technology (Graus et al., 2010; Jordan et al., 2009), a Proton Transfer Reaction Quadrupole Mass Spectrometer (PTR-MS) (Hansel et al., 1995), a fast online gas chromatograph coupled to a mass spectrometer (TOGA: Trace Organic Gas Analyzer) (Apel et al., 2003, 2010; Hornbrook et al., 2011), an optical technique to measure formaldehyde using the Fiber Laser-Induced Fluorescence instrument (FILIF) (DiGangi et al., 2011) and a thermal decomposition Chemical Ionization Mass Spectrometer (PAN-CIMS)
(Zheng et al., 2011). In addition to the real-time VOC measurements, whole air canisters were sampled at the site regularly throughout the study and analyzed post-study using a multi-column, multi-detector laboratory GC technique (Zhou et al., 2008; Russo et al., 2010).

To our knowledge this is the first time that this set of different VOC techniques are compared under natural conditions above a ponderosa pine forest for several days. Novel online instruments such as the FILIF and the PTR-TOF-MS were compared with already established instruments such as TOGA, PTR-MS and PAN-CIMS.

In this work we compare measurements of directly emitted biogenic VOCs, common oxidized VOCs as well as anthropogenic VOCs transported to this field site. We discuss the observed agreement as well as discrepancies between the different measurements for co-measured VOC species. This comparison adds to our knowledge and understanding of biases involved in the VOC measurement techniques and identifies the cause of some measurement uncertainties. It will ultimately serve to improve our ability to measure VOCs in a forested environment.

\section{Experimental}

During the BEACHON-ROCS field campaign in summer of 2010 a suite of instruments for VOC, nitrogen species, and oxidant measurements were combined with different sampling systems to probe soil and branch emissions, as well as ecosystem scale flux emissions. A full list of instrumentation can be found at the BEACHON data repository and webpage (https://wiki.ucar.edu/display/mfo/ Manitou+Forest+Observatory). During the period of 10-21 August 2010 simultaneous VOC measurements were conducted by different instruments. A list of all instruments used for this comparison is given in Table 1 as well as information on calibration procedures, measurement accuracy and precision. A detailed description of the field site, inlet systems and the instruments can be found in the Sects. 2.1-2.6.

\subsection{Field site}

The BEACHON-ROCS study was located at the Manitou Forest Observatory in the US Forest Service Manitou Experimental Forest near Woodland Park, Colorado, USA (2370 m elev., lat. $39^{\circ} 6^{\prime} 2^{\prime \prime} \mathrm{N}$, long. $105^{\circ} 6^{\prime} 9^{\prime \prime} \mathrm{W}$ ) in August 2010. The Manitou Forest is representative of the montane ponderosa pine zone in the Front Range, which extends from southern Wyoming to northern New Mexico. The site is part of the semi-arid (annual total of $505 \mathrm{~mm}$ of precipitation measured at the site from 1 October 2009 through 30 September 2010) Western US where biosphere and atmosphere exchange processes of energy, water, carbon and nitrogen are particularly sensitive to changes in precipitation (Kim et al., 2010). The canopy is open and of varying density, with mixed 
Table 1. List of instruments.

\begin{tabular}{|c|c|c|c|c|c|c|c|c|}
\hline Abbreviation & $\begin{array}{l}\text { Institute } \\
\text { Name }\end{array}$ & $\begin{array}{l}\text { Instrument } \\
\text { type }\end{array}$ & Accuracy & $\begin{array}{l}\text { Precision } \\
\text { @ } 1 \text { ppbv }\end{array}$ & $\begin{array}{l}\text { Limit of } \\
\text { detection }\end{array}$ & $\begin{array}{l}\text { Standard } \\
\text { used }\end{array}$ & $\begin{array}{l}\text { Sampling time } \\
\text { for comparison }\end{array}$ & $\begin{array}{l}\text { Frequency of } \\
\text { background } \\
\text { measurements }\end{array}$ \\
\hline PTR-TOF-MS & $\begin{array}{l}\text { University of } \\
\text { Innsbruck }\end{array}$ & PTR-TOF-MS & $\pm 15 \%$ & $2 \%(7 \% \text { for PAN })^{\mathrm{a}}$ & $\begin{array}{l}1-20 \text { pptv } \\
(50 \text { pptv for } \\
\text { PAN })^{a}\end{array}$ & NOAA & $6 \mathrm{~min}$ & $\begin{array}{l}\text { Every } 7 \mathrm{~h} \text { for } \\
30 \mathrm{~min}\end{array}$ \\
\hline PTR-MS & NCAR & PTR-MS (Ionicon) & $\pm 15 \%$ & $5 \% \mathrm{~b}$ & $0.2-1 \mathrm{pptv}^{\mathrm{b}}$ & NOAA & $15 \mathrm{~min}$ & $\begin{array}{l}\text { Every } 2.5 \mathrm{~h} \text { for } \\
7 \mathrm{~min}\end{array}$ \\
\hline TOGA & NCAR & GC/MS & $\pm 15 \%$ & $5 \% \mathrm{c}$ & $0.2-20 \mathrm{pptv}^{\mathrm{c}}$ & $\begin{array}{l}\text { NIST, NCAR, } \\
\text { NOAA }\end{array}$ & $10 \mathrm{~min}$ & $\begin{array}{l}\text { Twice a day for } \\
10 \text { min }(5 \\
\text { samples) }\end{array}$ \\
\hline PAN-CIMS & NCAR & CIMS & $\pm 12 \%$ & $\pm 2 \% \mathrm{~d}$ & $5 \mathrm{ppt}^{\mathrm{d}}$ & $\begin{array}{l}\text { In-situ, based on } \\
\text { NIST } \\
\text { Traceable NO } \\
\text { standard }\end{array}$ & $6 \mathrm{~min}$ & $\begin{array}{l}\text { Every } 30 \mathrm{~min} \text { for } \\
30 \mathrm{~s}\end{array}$ \\
\hline FILIF & $\begin{array}{l}\text { University of } \\
\text { Wisconsin }\end{array}$ & LIF & $\pm 30 \%$ & $10 \%{ }^{\mathrm{e}}$ & $200 p_{p t v}{ }^{\mathrm{e}}$ & $\begin{array}{l}\text { formaldehyde } \\
\text { permeation } \\
\text { device }\end{array}$ & $6 \mathrm{~min}$ & $\begin{array}{l}\text { Every } 5 \mathrm{~min} \text { for } \\
10 \mathrm{~s}\end{array}$ \\
\hline
\end{tabular}

${ }^{\text {a }}$ Precision and $2 \sigma$ detection limits are calculated for an integration time of $1 \mathrm{~min}$.

b $2 \sigma$ detection limit is calculated for an integration time of $15 \mathrm{~min}$.

$\mathrm{c}$ Precision and $2 \sigma$ detection limits are calculated for an integration time of $40 \mathrm{~s}$.

$\mathrm{d}$ Precision and $2 \sigma$ detection limits are calculated for an integration time of $1 \mathrm{~s}$.

e Precision and $2 \sigma$ detection limit are calculated for a $1 \mathrm{~s}$ integration time.

age ponderosa pine up to $100 \mathrm{yr}$ old and a surface cover of grasses, sage, crocus, forbs and exposed cryptogrammic soils. The average tree height surrounding the measurement tower is $18.5 \mathrm{~m}$. Further details about the site can be found elsewhere (Kim et al., 2010; DiGangi et al., 2011).

Details on the atmospheric conditions such as wind direction and history of the air mass are presented in Fry et al. (2013) for this site during July and August 2011. The synoptic wind patterns were the same during the BEACHON ROCS study in August 2010. Nighttimes were influenced by drainage flows down the valley from south and southwest. During the day wind shifts either to the west, which usually brings very clean air to the site or comes from an upslope flow from the east (NE to SE) which typically brings pollution from the Front Range. Typically days were sunny in the morning and some clouds build up in the afternoon. During this comparison most of the days were dry with a small amount of precipitation on 19 August. Relative humidity changed from 10-20\% during the day to $70-90 \%$ during the night. The change of sign in the temperature difference measured at 25 and $2 \mathrm{~m}$ above ground gives an indication on the stability of the atmosphere. Unstable conditions were observed during the day between 8 a.m. and 4 p.m. and stabile conditions during the night. Measurements of photosynthetic active radiation show the sunrise at $6 \mathrm{a}$.m. and sunset around 6 p.m. A $30-\mathrm{m}$ tower equipped with a profiling system and turbulence measurement capabilities was supported by the National Center for Atmospheric Research (NCAR). Three sampling inlet systems were used by the realtime VOC instruments, all of them were not heated. The first was a gradient inlet system used by the PTR-MS, it consisted of six continuously flushed Teflon (PTFE) lines (OD: 1/4 in.) mounted at $1,2.3,7,10,15.5$ and $23 \mathrm{~m}$ above ground. An automated valve system controlled the sampling by switching between inlets every $5 \mathrm{~min}$. A second (eddy-covariance, EC) inlet, was used by PTR-TOF-MS, PTR-MS, TOGA and PAN-CIMS and consisted of an approximately $35-\mathrm{m}$ inlet line (OD: $3 / 8 \mathrm{in}$.) mounted at $25.1 \mathrm{~m}$ on the tower. The FILIF instrument used a third gradient inlet system described in detail by DiGangi et al. (2011). In this work, measurements from the EC inlet at $25.1 \mathrm{~m}$ ( $\sim 20$ SLPM flow) and the top level of the FILIF inlet system at $25.1 \mathrm{~m}$ ( $\sim 80$ SLPM flow) are compared. PTR-MS measured from at the gradient inlet as well as on the EC inlet. For this comparison we use only PTR-MS data from the EC inlet. A fourth inlet, located at $10.7 \mathrm{~m}$, was used for the whole air canister sampling. All inlet lines had a length of about $35 \mathrm{~m}$.

\subsection{PTR-TOF-MS and PTR-MS}

Two Proton Transfer Reaction Mass Spectrometer systems measured VOCs during BEACHON-ROCS. One instrument used a quadrupole mass-analyzer (QMS) and the other employed a time of flight mass analyzer (TOF-MS). The QMS instrument was operated by NCAR and will be referred to as PTR-MS as is common practice. The TOF-MS instrument was operated by the University of Innsbruck and will be referred to as PTR-TOF-MS. PTR-MS instruments use hydronium ions $\left(\mathrm{H}_{3} \mathrm{O}^{+}\right)$as reagent ions to ionize organic compounds with little or no fragmentation. PTR-MS combines a PTR drift tube and the quadrupole mass spectrometer, which allows for fast detection of different VOCs at typically one compound per second with a low limit of detection. (Ionicon, Austria) (Lindinger et al., 1998; Hansel et al., 1995). The recently-developed high resolution PTR-TOF-MS (Müller et al., 2010; Jordan et al., 2009; Graus et al., 2010) couples the 
PTR ionization method with a time of flight mass spectrometer, which provides full mass spectra (in this study up to about $\mathrm{m} / \mathrm{z} 315$ ) within a fraction of a second at a high mass resolving power, allowing for the separation of isobaric species and determination of sum formulas.

PTR-TOF-MS: This instrument, developed at the University of Innsbruck (Graus et al., 2010), sampled continuously from the EC inlet during the study. Individual mass spectra up to $\mathrm{m} / \mathrm{z} 315$ were recorded every $0.1 \mathrm{~s}$. For the comparison and improved limit of detection, the $10-\mathrm{Hz}$ data were integrated to generate 6-min. mixing ratio averages. Data evaluation including mass scale calibration via continuous addition of di- and trichlorobenzene, was conducted on the 6-min. averages using MATLAB (Mathworks, USA) based functions described in detail by Müller et al. (2010). The drift tube was operated at $580 \mathrm{~V}$ drift voltage, $2.3 \mathrm{mbar}$ drift tube pressure and heated to $60^{\circ} \mathrm{C}$. This corresponds to an $E / N$ ratio of $125 \mathrm{Td}$ ( $E$ is the electric field strength and $N$ the gas number density; $1 \mathrm{Td}=10^{-17} \mathrm{~V} \mathrm{~cm}^{2}$ ). Every seven hours a 25 -min background measurement cycle was conducted by drawing the sample air through a custom catalytic converter, which was heated to $350^{\circ} \mathrm{C}$ (EnviCat ${ }^{\circledR V O C}$ 5538, Süd-Chemie AG, Germany). Compoundspecific limits of detection (LOD) were determined from the $2 \sigma$ uncertainty of background measurements and range from 2 to $20 \mathrm{pptv}$ (50 pptv for PAN) for a $1 \mathrm{~min}$ integration time. The instrument was calibrated once per week using a calibration gas standard, which was gravimetrically prepared and provided by NOAA according to protocols outlined by Montzka et al. (1993). The standard contains methanol (1.89 ppmv), acetonitrile $(2.00 \mathrm{ppmv})$, acetaldehyde (3.53 ppmv), acetone (1.99 ppmv), methyl vinyl ketone (1.1 ppmv), limonene (2.1 ppmv), 2-methyl-3-buten2-ol (2.2 ppmv), pyrrole (2.1 ppmv), benzene (1.49 ppmv), toluene (2.3 ppmv) and methyl ethyl ketone (2.2 ppmv), with an uncertainty of $\pm 5 \%$. The standard was dynamically diluted into purified ambient air to obtain typical calibration gas mixtures ranging from 1 to $10 \mathrm{ppbv}$ (part per billion by volume). Compound-specific sensitivities were determined from the slopes of four-point calibrations. An accuracy of $15 \%$ was calculated when accounting for the uncertainties of the gas standard $(5 \%)$ and the dilution system $(10 \%)$, which corresponds to the $13 \%$ variance in the seven calibrations conducted during the measurement campaign. The absolute humidity ranged from $10-25 \mathrm{mmol} \mathrm{mol}^{-1}$ during the comparison period. The six on side calibrations cover an absolute humidity range of $14-25 \mathrm{mmol} \mathrm{mol}^{-1}$. The sensitivity variation within this humidity range was smaller than $4 \%$ and therefore clearly within the stated accuracy which justifies the use of an average sensitivity over the whole humidity range. The precision measured at $1 \mathrm{ppbv}$ for a $1 \mathrm{~min}$ integration time is $2 \%$. The calibration standard available during this study included methyl vinyl ketone (MVK) but no methacrolein (MAC). As shown by Liu et al. (2012) the sensitivities for MVK and MAC are very similar. Further- more Zhao and Zhang (2004) calculated that the reaction rate coefficients for both compounds are similar. Therefore the calibrated sensitivity for MVK is also used for MAC. Peroxyacetyl nitrate (PAN) was calibrated once during the field campaign using the same gas standard as described in Sect. 2.5. For PAN we calculated a precision of $7 \%$.

Formaldehyde has to be treated separately regarding the total error estimation as formaldehyde sensitivities are highly water dependent. In the presence of water in the drift tube the protonated formaldehyde can react with water. This so-called backward reaction can be accounted for by calculating waterdependent sensitivities described by Hansel et al. (1998). As the exact amount of water in the drift tube is unknown, the sensitivity calculation is adjusted to calibrations conducted before the field campaign using a calibration gas standard (Apel Riemer Inc., USA), that was dynamically diluted similarly as described above. A permeation tube for frequent formaldehyde calibrations at varying humidity of the sample air throughout the study as suggested by Warneke et al. (2011) was not available at the time. Molecular fragments resulting in the same $\mathrm{m} / \mathrm{z}$, ratio as formaldehyde are conceivable; one possible candidate would be methyl hydroperoxide. The total measurement error for formaldehyde cannot be calculated in the same way as for the other calibrated species and is estimated to be $\pm 50 \%$ concerning the described uncertainties.

PTR-MS: A redesigned PTR-MS instrument (Karl et al., 2009) based on a commercial instrument (Ionicon Analytik $\mathrm{GmbH}$, Austria) was operated at $2.3 \mathrm{mbar}$ drift pressure and $540 \mathrm{~V}$ drift voltage. The drift-tube was held at a constant temperature of $40^{\circ} \mathrm{C}$ leading to an $E / N$ of $110 \mathrm{Td}$. The system alternated between gradient, eddy covariance and background measurements, spending 110 min measuring on the gradient inlets followed by $34 \mathrm{~min}$ on the EC inlet and $7 \mathrm{~min}$ of background measurements sampling air through a catalytic converter. Switching between measurements was computer-controlled. The gradient data are interpolated such that a full gradient cycle was obtained every $90 \mathrm{~min}$. This equates to three averaged gradient cycles at six heights and represents a 15-min average at each height. For this work only the data from the $23 \mathrm{~m}$ gradient inlet is used. The instrument was calibrated using the same gas standard as the PTR-TOF-MS. Additional calibrations using a second gas standard (Scott-Marrin, Riverside, CA, USA) were conducted three times during the campaign. The second VOC gas standard included a mixture of acetaldehyde (5.84 ppmv, $\pm 3 \%$ ), acetone (5.66 ppmv, $\pm 3 \%$ ), acetonitrile (5.44 ppmv, $\pm 10 \%)$, methanol (4.6ppmv, $\pm 3 \%$ ) and toluene $(5.74 \mathrm{ppmv}, \pm 3 \%)$. Sensitivities varied between those of benzene $\left(11 \pm 3 \mathrm{ncps}_{\mathrm{ppbv}}{ }^{-1}\right)$ and acetone $\left(26 \pm 5 \mathrm{ncps} \mathrm{ppbv}^{-1}\right)$. For a $15-\mathrm{min}$ average, this resulted in LODs between $0.2 \mathrm{pptv}$ and $1 \mathrm{pptv}$ respectively. The precision is estimated to be better than $5 \%$. The accuracy $( \pm 15 \%)$ is determined from a combined uncertainty of gas standards and the dilution system. 


\subsection{TOGA}

The NCAR Trace Organic Gas Analyzer (TOGA) uses fast online gas chromatography coupled with mass spectrometry (GS-MS) to analyze 40-s integrated samples taken as often as once every 2 min. During the BEACHON-ROCS field study, samples were taken every 5-10 min and about two thirds of those samples have been analyzed for 37 targeted VOCs. The instrument has been described previously by Apel et al. (2010). Briefly, the primary system components include a cryogenic preconcentrator, a gas chromatograph (GC), a mass spectrometer (MS), and a zero air/calibration system. All processes and data acquisition are computer controlled. Three traps are used during the sampling and preconcentration steps: a water trap, an enrichment trap packed with glass wool, and a cryofocusing trap, with no adsorbents in any of the traps. The GC is a custom-designed unit that is lightweight and temperature programmable, fitted with a Restek MTX-624 column (I.D. $=0.18 \mathrm{~mm}$, length $=8 \mathrm{~m}$ ). The system was calibrated with a National Institute for Standards and Technology (NIST) 16-component NMHC standard, and an in-house gravimetrically-prepared mixture containing a mixture of OVOCs, NMHCs and halogenated VOCs. Post-study calibrations were performed to obtain response factors for four compounds that were not in either standard; this included MBO. Calibrations for MBO were made using the standard used by both PTRTOF-MS and PTR-MS. For the monoterpenes, only calibration standards for $\alpha$-pinene, $\beta$-pinene and camphene have been used to date, and the sensitivities for other monoterpenes or monoterpene groups have been estimated based on relative known fragmentation patterns. The 37 VOCs observed by TOGA during BEACHON-ROCS include NMHC $\left(\mathrm{C}_{4}\right.$ and $\mathrm{C}_{5}$ alkanes, isoprene, benzene, toluene, $\mathrm{C}_{8}$-aromatic hydrocarbons, 1,3,5-trimethylbenzene, 1,2,4trimethylbenzene, $\alpha$-pinene, $\beta$-pinene, limonene, carene, myrcene and camphene), oxygenated NMOCs (acetaldehyde $\left(\mathrm{CH}_{3} \mathrm{CHO}\right)$, methanol $\left(\mathrm{CH}_{3} \mathrm{OH}\right)$, ethanol $\left(\mathrm{C}_{2} \mathrm{H}_{5} \mathrm{OH}\right)$, acetone $\left(\mathrm{CH}_{3} \mathrm{COCH}_{3}\right)$, propanal $\left(\mathrm{C}_{2} \mathrm{H}_{5} \mathrm{CHO}\right)$, methacrolein (MAC; $\mathrm{CH}_{2} \mathrm{C}\left(\mathrm{CH}_{3}\right) \mathrm{CHO}$ ), methyl vinyl ketone (MVK; $\mathrm{CH}_{2} \mathrm{CHCOCH}_{3}$ ), 2-methyl-3-buten-2-ol (MBO); butanal $\left(\mathrm{C}_{3} \mathrm{H}_{7} \mathrm{CHO}\right)$, methyl ethyl ketone (MEK, $\left.\mathrm{C}_{2} \mathrm{H}_{5} \mathrm{COCH}_{3}\right)$ methyl tert-butyl ether (MTBE; $\left.\mathrm{C}\left(\mathrm{CH}_{3}\right)_{3} \mathrm{OCH}_{3}\right)$, 1,8cineole, halogenated NMOCs (chloromethane $\left(\mathrm{CH}_{3} \mathrm{Cl}\right.$ ), bromomethane $\left(\mathrm{CH}_{3} \mathrm{Br}\right)$, dichloromethane $\left(\mathrm{CH}_{2} \mathrm{Cl}_{2}\right)$, chloroform $\left(\mathrm{CHCl}_{3}\right)$, tetrachloromethane $\left.\left(\mathrm{CCl}_{4}\right)\right)$, acetonitrile $\left(\mathrm{CH}_{3} \mathrm{CN}\right)$ and dimethylsulfide (DMS; $\left.\mathrm{CH}_{3} \mathrm{SCH}_{3}\right)$. This study marks the first time monoterpenes were observed using TOGA. Speciated monoterpene mixing ratios reported by TOGA include $\alpha$-pinene, camphene, the sum of $\beta$-pinene, carene and myrcene, the sum of limonene and 1,8-cineole, and the sum of other monoterpenes. TOGA did not distinguish between limonene and 1,8-cineole, a monoterpene alcohol, therefore 1,8-cineole is part of the sum of monoterpenes. For this work, the sum of all the above monoterpenes was used in the comparisons against data from the PTR(TOF)-MS systems. LODs defined as signal to noise equal to 5 of chromatographic peaks ranged between $0.2 \mathrm{pptv}$ and $20 \mathrm{pptv}$ for the targeted species. The precision is estimated to be better than $5 \%$. The accuracy $( \pm 15 \%)$ was determined from a combined uncertainty of the gas standards and the uncertainties in the mass flow controllers in the dilution system, but the accuracy for the sum of the monoterpenes is lower $( \pm 25 \%)$ because the calibration factors for some of the terpenes measured are only an estimate.

\subsection{FILIF}

Formaldehyde was measured by the UW Fiber LaserInduced Fluorescence (FILIF) instrument (DiGangi et al., 2011) using a 32-pass White-type multipass cell and $\sim 10$ $\mathrm{mW}$ of $353 \mathrm{~nm}$ light. Ambient air was sampled using 3/8-in. I.D. PFA Teflon inlets with lengths of $30-45 \mathrm{~m}$ at $25.1 \mathrm{~m}$, $17.7 \mathrm{~m}, 8.5 \mathrm{~m}$, and $1.6 \mathrm{~m}$ above ground level, typically at $\sim 80$ SLM and $10 \mathrm{~Hz}$ for the $25.1 \mathrm{~m}$ inlet and $\sim 10$ SLM and $1 \mathrm{~Hz}$ for the other three sampling heights. Inlet and zeroing analyses resulted in no detectable artifacts (DiGangi, 2012). Calibrations were performed weekly using a formaldehyde permeation device, cross-calibrated via FTIR to have a $438 \mathrm{ng} \mathrm{min}^{-1}$ permeation rate (DiGangi et al., 2011), diluted using air from a zero-air generator (AADCO 737-series). The uncertainty in the permeation rate limited the overall accuracy of $\mathrm{HCHO}$ mixing ratios to approximately $30 \%$. Field detection limits $(2 \sigma)$ during the BEACHON-ROCS campaign were typically $\sim 200 \mathrm{pptv}$ in $1 \mathrm{~s}$.

\subsection{PAN-CIMS}

The PAN-CIMS is a compact chemical ionization mass spectrometer designed primarily for airborne measurements. It is based on thermal decomposition of the peroxyacyl nitrate species in a heated inlet region (typically $150^{\circ} \mathrm{C}$, but variable depending on application) and detection of the parent peroxy alkyl radicals with $\mathrm{I}^{-}$ion chemistry. The instrument is based on an original design by Slusher et al. (2004) and has been described in detail by Zheng et al. (2011). PAN (peroxyacetyl nitrate) and a number of longer-chain homologues can be accurately measured with the PAN-CIMS. The instrument is based on a 3/8-in. MBB Extrel quadrupole mass spectrometer system and can measure PAN with a maximum time resolution of $4 \mathrm{~Hz}$, depending on the number of PAN species measured. Typically, calibration gas $\left({ }^{13} \mathrm{C}\right.$-labeled PAN made in-situ in a photo-reactor) is added to the sample stream continuously, and measured concurrently with ambient PAN and selected homologues.

During BEACHON-ROCS, the PAN-CIMS sampled continuously from the EC inlet line and in the interest of high time resolution, only PAN and PPN were measured. The 1$\mathrm{S}$ data was averaged over $6 \mathrm{~min}$ for comparison purposes. Background measurements were taken every $30 \mathrm{~min}$. and a 

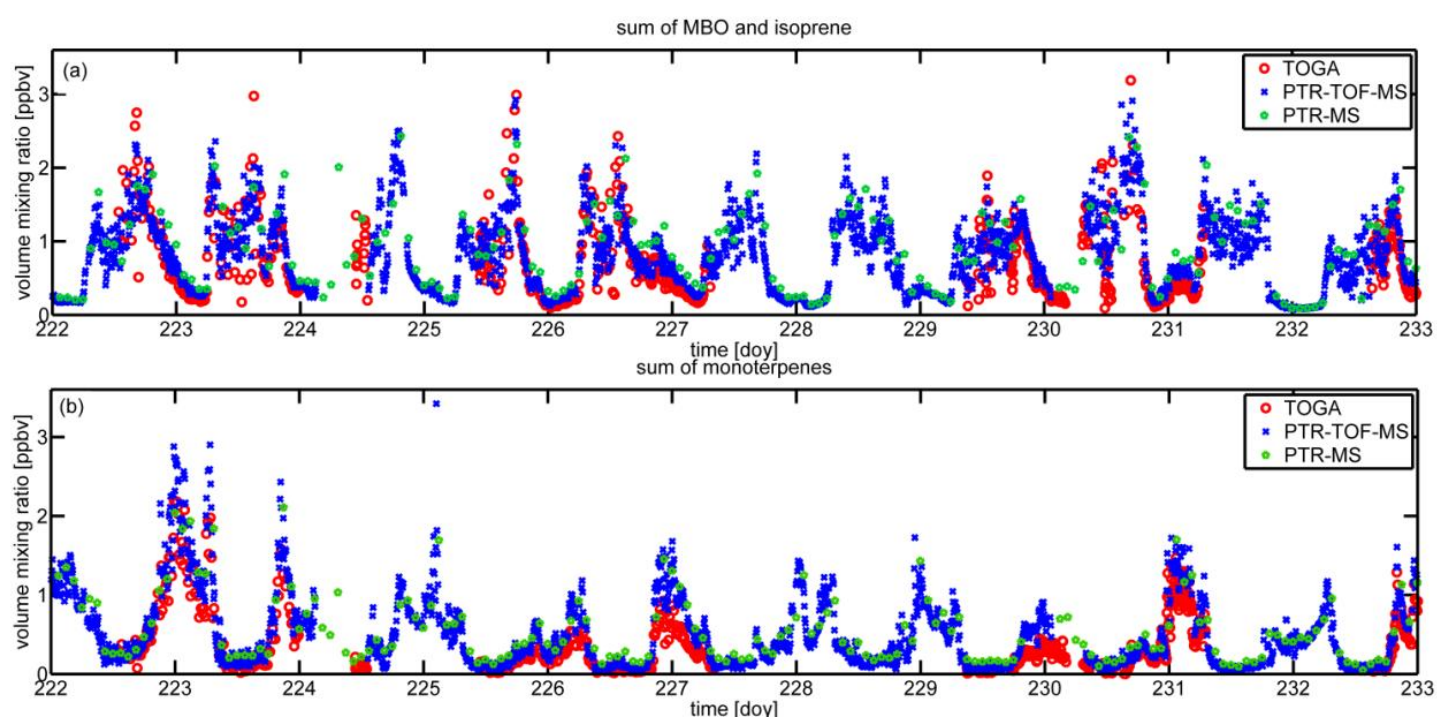

Fig. 1. 11-day time series of (a) the sum of MBO and isoprene and (b) the sum of monoterpenes during the BEACHON ROCS campaign in summer 2010 measured by three different instruments: PTR-TOF-MS (blue), TOGA (red) and PTR-MS (green) measured at 25.1 m.

limit of detection of about 5-10 pptv was achieved. The instrument accuracy is calculated by error propagation of measured uncertainties of the flow tube pressure, the (reported) flow controller accuracy, the measured decomposition temperature, and the standard source output variability (determined in the laboratory), listed in descending importance. The instrument precision of $\pm 2 \%$ is calculated from the observed variation in the continuously measured calibration standard.

\subsection{Other measurements}

Water concentrations are measured at $25.1 \mathrm{~m}$ with a LI-7000 infrared gas analyzer (LI-COR, Lincoln NE, USA). Whole air samples were collected throughout the study by filling 2L evacuated stainless steel canisters to approximately $30 \mathrm{psi}$ using a high-purity metal bellows pump, shipped to the University of New Hampshire and analyzed within two months of sample collection using a multi-column multi-detector GC system (Zhou et al., 2008; Russo et al., 2010). Generally, a minimum of four whole air samples were collected each day at 02:00, 08:00, 14:00 and 20:00, but at times the sampling frequency was as high as once per hour. The inlet for the whole air samples was located below the forest canopy at a height of $10.7 \mathrm{~m}$ on the tower, and for this reason the VOC measurements from the canisters are not rigorously compared to the real-time VOC measurements made at 23-m to 25-m tower location in this work.

\subsection{Statistical methods}

All real-time VOC datasets were obtained at slightly different heights, time resolutions and analysis or collection times. All measurements were averaged to $5-6 \mathrm{~min}$ bins be- fore the comparison. Linear interpolation was used where time stamps did not coincide. For the regressions between measurements from two instruments, errors of both datasets are important. To account for errors in $\mathrm{x}$ and $\mathrm{y}$ the regression was based on a reduced major axis fit (Helsel and Hirsch, 1993). The correlation coefficient $(R)$ was calculated as a measure of the overall agreement between measurements. Slope discrepancies given in $\%$ are relative deviations from the ideal slope 1 . Slopes and intercepts of the regression with error estimates as well as the correlation coefficient $R$ and the number of data points $(N)$ available for each comparison pair of data are given in Table 1.

\section{Results}

Figure 1 shows 11 days (10-21 August) of continuous mixing ratio measurements of the sum of 2-methyl-3-buten-2ol (MBO) and isoprene (Fig. 1a) and the sum of monoterpenes (Fig. 1b). PTR-TOF-MS, PTR-MS and TOGA measured these compounds at $25.1 \mathrm{~m}$ during the campaign. MBO, methanol and monoterpenes were previously found to be the most abundant VOCs at this site (Kim et al., 2010). The sum of MBO and isoprene and the sum of monoterpenes depict typical diurnal mixing ratio trends for a temperature (monoterpenes) and light and temperature (MBO, isoprene) dominant emission pattern. Monoterpenes showed a typical diurnal pattern with low mixing ratios $(0.1-0.2 \mathrm{ppbv})$ during daytime and maximum mixing ratio up to 3 ppbv during nighttime hours. In contrast, the sum of MBO and isoprene reached a maximum during the day (up to $6 \mathrm{ppbv}$ ) and exhibited low mixing ratios, typically averaging between 0.2 to $0.4 \mathrm{ppbv}$ at night. The diurnal cycle of MBO and isoprene 

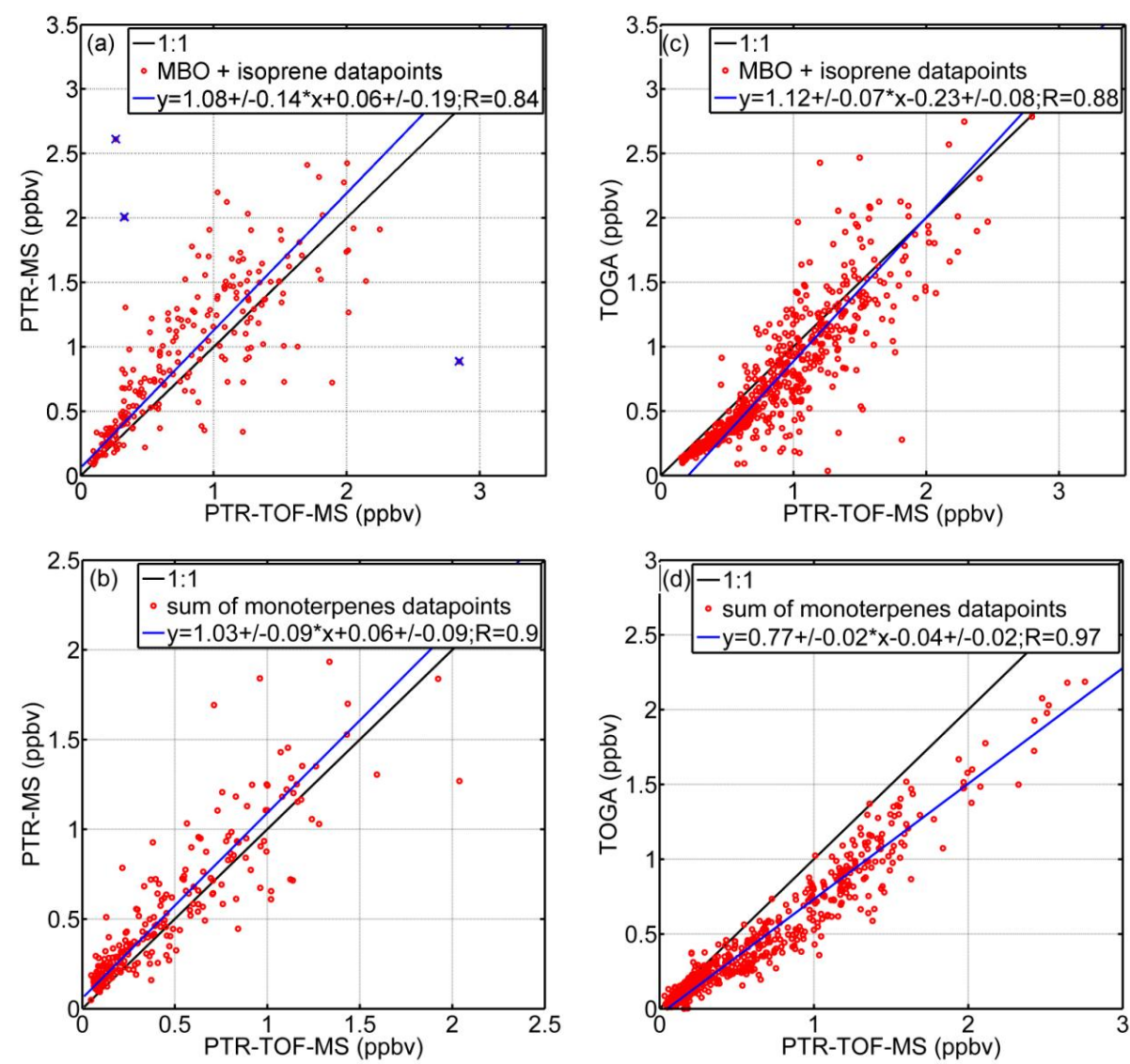

Fig. 2. Scatter plots and linear regressions for the dominant species (the sum of MBO and isoprene and the sum of monoterpenes) as examples for the results summarized in table 2. Panels (a) and (b) compare PTR-TOF-MS and PTR-MS, and (c) and (d) compare PTR-TOF-MS and TOGA.

mixing ratios are characteristic for a predominantly lightdependent emission pattern, while the sum of monoterpenes reflects a largely temperature-dependent emission pattern, allowing the accumulation of mixing ratio in the shallow stable nocturnal boundary layer. This has been described previously in detail for this site by Kim et al. (2010).

Figure 2 shows examples of scatter plots and regressions between the instruments for the sum of MBO and isoprene and the sum of monoterpenes. Figure $2 \mathrm{a}$ and $\mathrm{b}$ show the correlation between PTR-TOF-MS and PTR-MS. These two instruments are in good agreement for both plotted species with slopes of $1.08 \pm 0.14$ for the sum of MBO and isoprene and $1.03 \pm 0.09$ for the sum of monoterpenes. Comparison of measurements with different time stamps can be especially challenging when measured directly above a strong source within a turbulent environment. This is here the case for the sum of MBO and isoprene. Three measurement points marked with blue crosses in Fig. 2a were omitted from the comparison, as interpolation was not justified for these points. Figure $2 \mathrm{c}$ and d compare both VOC species for PTR-TOF-MS and TOGA displaying good agreement for the sum of MBO and isoprene with a slope of 1.12 \pm 0.07 .
The agreement was less for the sum of monoterpenes, with a slope of $0.77 \pm 0.02$ but still within the stated uncertainties of the measurements. In Table 2, information on the regressions between all instruments and all measured species are given. The same information is visualized in Fig. 3 showing correlation coefficients (Fig. 3a) and slopes of the regression (Fig. 3b) taken from Table 2.

In the following paragraphs we describe all VOC species that were compared. For each VOC comparison we include the protonated ion mass measured by the PTR-(TOF)-MS systems. The ion masses are given as a nominal mass to charge $(\mathrm{m} / \mathrm{z})$ ratio for the QMS and the exact mass to charge ratio for the TOF-MS. As an example, methanol is measured at nominal $\mathrm{m} / \mathrm{z} 33$ using a QMS and has the exact mass of 33.0335. In the following discussion mass to charge ratios will be indicated as $\mathrm{m} / \mathrm{z} 33(.0335)$ to illustrate the difference between the two mass analyzers. When only one instrument type is discussed $m / z 33$ is used for QMS and $m / z 33.0335$ for TOF-MS.

2-methyl-3-butene-2-ol (MBO) and isoprene: It has been shown that $\mathrm{MBO}$ has a characteristic fragmentation pattern in PTR-(TOF)-MS (Fall et al., 2001). Protonated MBO is 
Table 2. Results of the measurement comparison.

\begin{tabular}{|c|c|c|c|c|c|c|}
\hline Species & Technique & Units & Slope & Intercept & $R$ & $N$ \\
\hline \multirow[t]{3}{*}{$\mathrm{MBO}+$ isoprene } & PTR-MS vs. PTR-TOF-MS & ppbv & $1.08 \pm 0.14$ & $0.06 \pm 0.19$ & 0.84 & 234 \\
\hline & TOGA vs. PTR-TOF-MS & ppbv & $1.12 \pm 0.07$ & $-0.23 \pm 0.08$ & 0.88 & 634 \\
\hline & TOGA vs. PTR-MS & ppbv & $1.11 \pm 0.39$ & $-0.39 \pm 0.59$ & 0.72 & 78 \\
\hline \multirow[t]{3}{*}{ sum of monoterpenes } & PTR-MS vs. PTR-TOF-MS & ppbv & $1.03 \pm 0.09$ & $0.06 \pm 0.09$ & 0.90 & 237 \\
\hline & TOGA vs. PTR-TOF-MS & ppbv & $0.77 \pm 0.02$ & $-0.04 \pm 0.02$ & 0.97 & 639 \\
\hline & TOGA vs. PTR-MS & ppbv & $0.79 \pm 0.10$ & $-0.08 \pm 0.13$ & 0.90 & 78 \\
\hline \multirow[t]{3}{*}{ methanol } & PTR-MS vs. PTR-TOF-MS & ppbv & $1.10 \pm 0.09$ & $-0.29 \pm 0.62$ & 0.92 & 237 \\
\hline & TOGA vs. PTR-TOF-MS & ppbv & $0.90 \pm 0.03$ & $-0.74 \pm 0.28$ & 0.96 & 602 \\
\hline & TOGA vs. PTR-MS & ppbv & $0.80 \pm 0.08$ & $-0.18 \pm 0.96$ & 0.93 & 78 \\
\hline \multirow[t]{3}{*}{ acetaldehyde } & PTR-MS vs. PTR-TOF-MS & ppbv & $1.10 \pm 0.11$ & $-0.13 \pm 0.12$ & 0.89 & 237 \\
\hline & TOGA vs. PTR-TOF-MS & ppbv & $1.03 \pm 0.03$ & $-0.05 \pm 0.06$ & 0.96 & 639 \\
\hline & TOGA vs. PTR-MS & ppbv & $0.87 \pm 0.08$ & $0.22 \pm 0.19$ & 0.95 & 78 \\
\hline \multirow{3}{*}{ acetone + propanal } & PTR-MS vs. PTR-TOF-MS & ppbv & $0.90 \pm 0.07$ & $-0.05 \pm 0.31$ & 0.90 & 237 \\
\hline & TOGA vs. PTR-TOF-MS & ppbv & $1.16 \pm 0.05$ & $-0.65 \pm 0.18$ & 0.95 & 632 \\
\hline & TOGA vs. PTR-MS & ppbv & $1.17 \pm 0.21$ & $-0.28 \pm 0.64$ & 0.91 & 78 \\
\hline \multirow[t]{3}{*}{ acetonitrile } & PTR-MS vs. PTR-TOF-MS & ppbv & $1.02 \pm 0.11$ & forced to 0 & 0.88 & 237 \\
\hline & TOGA vs. PTR-TOF-MS & ppbv & $0.92 \pm 0.03$ & forced to 0 & 0.62 & 553 \\
\hline & TOGA vs. PTR-MS & ppbv & $0.89 \pm 0.55$ & forced to 0 & 0.74 & 78 \\
\hline \multirow[t]{3}{*}{ MVK + methacrolein } & PTR-MS vs. PTR-TOF-MS & $\mathrm{NaN}$ & $\mathrm{NaN}$ & $\mathrm{NaN}$ & $\mathrm{NaN}$ & $\mathrm{NaN}$ \\
\hline & TOGA vs. PTR-TOF-MS & ppbv & $0.63 \pm 0.02$ & $-0.02 \pm 0.01$ & 0.90 & 633 \\
\hline & TOGA vs. PTR-MS & $\mathrm{NaN}$ & $\mathrm{NaN}$ & $\mathrm{NaN}$ & $\mathrm{NaN}$ & $\mathrm{NaN}$ \\
\hline \multirow[t]{3}{*}{ MEK + butanal } & PTR-MS vs. PTR-TOF-MS & $\mathrm{NaN}$ & $\mathrm{NaN}$ & $\mathrm{NaN}$ & $\mathrm{NaN}$ & $\mathrm{NaN}$ \\
\hline & TOGA vs. PTR-TOF-MS & ppbv & $0.88 \pm 0.05$ & $0.03 \pm 0.02$ & 0.81 & 776 \\
\hline & TOGA vs. PTR-MS & $\mathrm{NaN}$ & $\mathrm{NaN}$ & $\mathrm{NaN}$ & $\mathrm{NaN}$ & $\mathrm{NaN}$ \\
\hline \multirow[t]{3}{*}{ benzene } & PTR-MS vs. PTR-TOF-MS & ppbv & $1.03 \pm 0.15$ & $0.00 \pm 0.10$ & 0.79 & 237 \\
\hline & TOGA vs. PTR-TOF-MS & ppbv & $1.00 \pm 0.04$ & $0.00 \pm 0.00$ & 0.93 & 621 \\
\hline & TOGA vs. PTR-MS & ppbv & $1.02 \pm 0.18$ & $0.00 \pm 0.01$ & 0.88 & 78 \\
\hline \multirow[t]{3}{*}{ toluene } & PTR-MS vs. PTR-TOF-MS & ppbv & $1.31 \pm 0.19$ & $0.00 \pm 0.01$ & 0.85 & 237 \\
\hline & TOGA vs. PTR-TOF-MS & ppbv & $0.98 \pm 0.04$ & $0.00 \pm 0.01$ & 0.94 & 610 \\
\hline & TOGA vs. PTR-MS & $\mathrm{NaN}$ & $\mathrm{NaN}$ & $\mathrm{NaN}$ & $\mathrm{NaN}$ & $\mathrm{NaN}$ \\
\hline \multirow[t]{3}{*}{$\mathrm{m} 93$} & PTR-MS vs. PTR-TOF-MS & ppbv & $0.99 \pm 0.09$ & $0.00 \pm 0.01$ & 0.90 & 237 \\
\hline & TOGA vs. PTR-TOF-MS & ppbv & $0.72 \pm 0.03$ & $0.00 \pm 0.01$ & 0.92 & 610 \\
\hline & TOGA vs. PTR-MS & ppbv & $0.74 \pm 0.10$ & $0.01 \pm 0.02$ & 0.86 & 78 \\
\hline PAN & TD-CIMS vs. PTR-TOF-MS & ppbv & $0.73 \pm 0.01$ & $0.08 \pm 0.01$ & 0.89 & 3069 \\
\hline formaldehyde & FILIF vs. PTR-TOF-MS & ppbv & $0.50 \pm 0.01$ & $0.26 \pm 0.07$ & 0.85 & 3246 \\
\hline
\end{tabular}

found at $m / z$ 87(.0805) with typical abundances of $13-25 \%$ of the total MBO signal, and the corresponding fragmention (water loss) at $\mathrm{m} / \mathrm{z}$ 69(.0699) with typical abundances of $87-75 \%$. The fragment of MBO therefore interferes with the isoprene signal $(\mathrm{m} / \mathrm{z}$ 69.0699) using a PTR-(TOF)-MS system. For this reason the comparison is performed on the sum of MBO and isoprene, which should theoretically be conserved. To evaluate the contribution of isoprene to the ambient $\mathrm{m} / \mathrm{z}$ 69(.0699) ion signal for the PTR-MS and PTR-TOF-MS measurements, the ratio of $\mathrm{m} / \mathrm{z}, 87(.0805)$ and $\mathrm{m} / \mathrm{z}$ 69(.0699) in the ambient air was compared to that obtained from an MBO calibration standard.

During the study, mixing ratios of the sum of MBO and isoprene were between $0.2 \mathrm{ppvb}$ during the night and $3 \mathrm{ppbv}$ during the day. PTR-MS, PTR-TOF-MS and TOGA are in good agreement within 8-12\%, well within the reported uncertainties for the measurements.
Since isoprene $\left(k_{\mathrm{OH}} \sim 10 \times 10^{-11} \mathrm{~cm}^{3}\right.$ molecule ${ }^{-1} \mathrm{~s}^{-1}$ (Zhang et al., 2000)) is about twice as reactive with $\mathrm{OH}$ as MBO $\left(k_{\mathrm{OH}} \sim 5.6 \times 10^{-11} \mathrm{~cm}^{3}\right.$ molecule ${ }^{-1} \mathrm{~s}^{-1}$ (Carrasco et al., 2007)) and has a higher secondary organic aerosol yield, it is important to evaluate the exact ratio in order to constrain the atmospheric chemistry (e.g. $\mathrm{OH}$ reactivity) at this site. For example an average ratio of $30 \%$ of isoprene would imply that it could potentially contribute $60 \%$ of the $\mathrm{OH}$ reactivity. A companion paper (Karl et al., 2012) is used to evaluate the accuracy of the isoprene/MBO ratio obtained by PTRMS and PTR-TOF-MS based on a novel ionization methodology that allows separation of these two species without any interference. The results suggest that the overall ratio calculated from PTR-MS and PTR-TOF-MS presented here should be accurate to within $25 \%$.

From the PTR-MS and PTR-TOF-MS measurements, a study average contribution of isoprene to the $\mathrm{m} / \mathrm{z}$ signal 


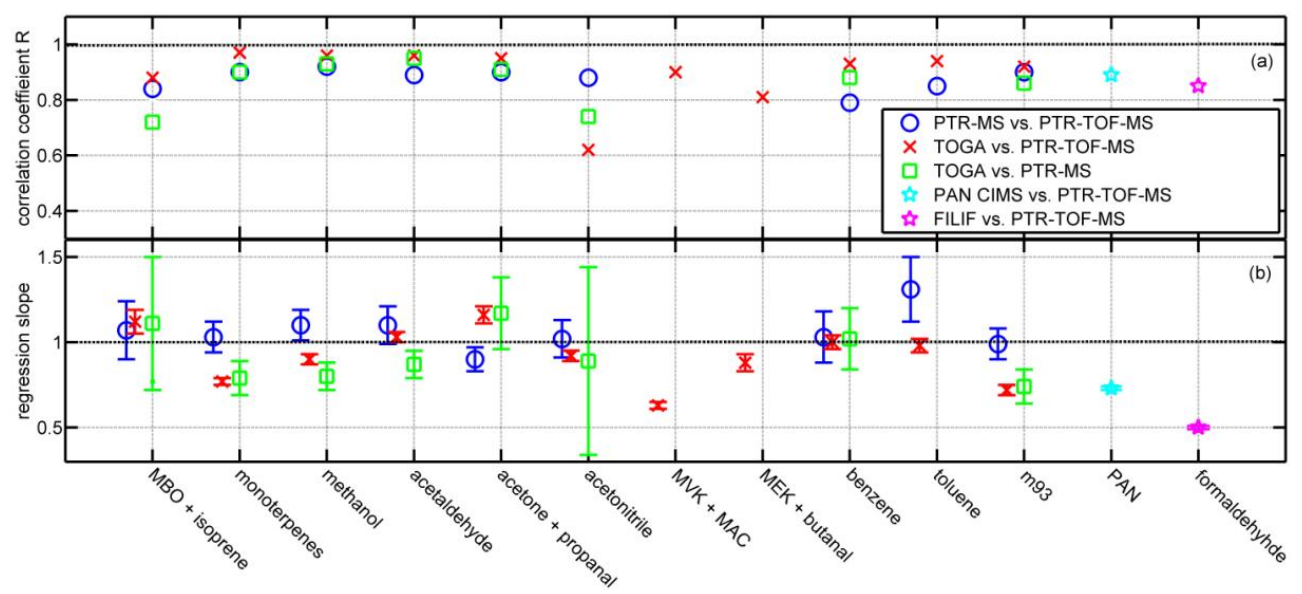

Fig. 3. A visualization of all comparisons showing correlation coefficients $R$ in (a) and the slopes from the regressions in (b).

69(.0699) is estimated by regressing $\mathrm{m} / \mathrm{z} 69(.0699)$ and $\mathrm{m} / \mathrm{z}$ 87(.0805), and comparing to a MBO calibration gas standard. Isoprene can then be estimated by comparing the theoretical contribution (based on the gas standard) of MBO to the measured signal $\mathrm{m} / \mathrm{z}$ 69(.0699) in ambient air. The measured difference between theoretical and ambient ratio will then give an estimate of the additive contribution of isoprene to $\mathrm{m} / z$ 69(.0699). From this difference we estimate a study average contribution of $7 \%$ (range 3-11\%) of isoprene relative to MBO based on the PTR-TOF-MS data. The same analysis based on the PTR-MS data yields $4 \%$ (range: 0 $6 \%)$. It is noted that the presented regression analysis is performed for the entire dataset rather than for individual data points.

Chromatographically, isoprene and MBO elute at different temperatures, and thus TOGA measurements provide individual mixing ratios for $\mathrm{MBO}$ and isoprene. Tests have been conducted using TOGA to determine if there is evidence that dehydration of $\mathrm{MBO}$ in the system results in conversion to isoprene. Standards containing MBO but not isoprene were analyzed under varying humidity conditions and no isoprene formation has been observed in the system.

During the BEACHON-ROCS study, the average isoprene/(isoprene $+\mathrm{MBO}$ ) ratio from the TOGA data was $0.25 \pm 0.11$, ranging between $2 \%$ and $65 \%$. Similarly, although these data are not being compared directly, the whole air sample data provide individual MBO and isoprene data as well. From 115 individual whole air samples in which $\mathrm{MBO}$ and isoprene were both observed, the average isoprene/(isoprene $+\mathrm{MBO}$ ) contribution is $0.17 \pm 0.09$. Isoprene could be either directly emitted or transported to the site, but based on previous work involving branch enclosures of ponderosa pine (Harley et al., 1998), it is not believed that isoprene is emitted locally in significant quantities. From a comparison of the TOGA and whole air samples, the isoprene mixing ratios observed inside the canopy in the whole air samples on average is $30 \%$ lower than the mixing ra- tios observed above the canopy by TOGA. Similarly, the isoprene contribution to the sum of isoprene $+\mathrm{MBO}$ reported by TOGA is greater than the ratio in the whole air samples. Both of these details are consistent with isoprene being advected to the site. Assuming that all isoprene is transported to the site and not directly emitted, the ratio of the TOGA-measured isoprene/(MVK + MAC) suggests a photochemical age range of $1-5 \mathrm{~h}$ and an average age of $2.5 \mathrm{~h}$ for isoprene-impacted air advected to the site. The photochemical age was calculated according to Apel et al. (2002). OH concentrations at this site discussed in detail by Kim et al. (2013) ranged from 1$6 \times 10^{6}$ molecules $\mathrm{cm}^{-3}$ and ozone concentrations from 5$70 \mathrm{ppbv}$. The source(s) of isoprene and its oxidation products MVK and MACR at this site are still unresolved and need to be studied further.

The sum of monoterpenes: Both PTR-(TOF)-MS systems used the monoterpene parent ion $\mathrm{m} / \mathrm{z} 137(.134)$ and the main monoterpene fragment $\mathrm{m} / \mathrm{z}$ 81.(0706) to calculate mixing ratios. Since PTR-(TOF)-MS does not distinguish between different isomers, all detected monoterpenes measured by TOGA ( $\alpha$-pinene, $\beta$-pinene, camphene, carene, myrcene, limonene, cineole and a set of other unidentified terpenes) were summed to compare with the monoterpene signal measured by the PTR-(TOF)-MS systems. Cineole is a monoterpene alcohol that was not separated from limonene by TOGA and is therefore coadded to the sum of total monoterpenes. During the field study mixing ratios for the sum of monoterpenes were observed as high as $1-3 \mathrm{ppbv}$ during the night and 50-100 pptv during the day. The good agreement of the PTR-TOF-MS and PTR-MS measurements is indicated by a slope of 1.03 for the sum of monoterpenes mixing ratios. Compared to TOGA the PTR-TOF-MS and PTR-MS systematically reported $21-23 \%$ higher monoterpene mixing ratios. During the BEACHON-ROCS about five percent of this difference could be explained by the presence of the oxygenated monoterpene, linalool. The fragmentation pattern of linalool was calibrated post the campaign: $\mathrm{m} / \mathrm{z}, 155.147$ 


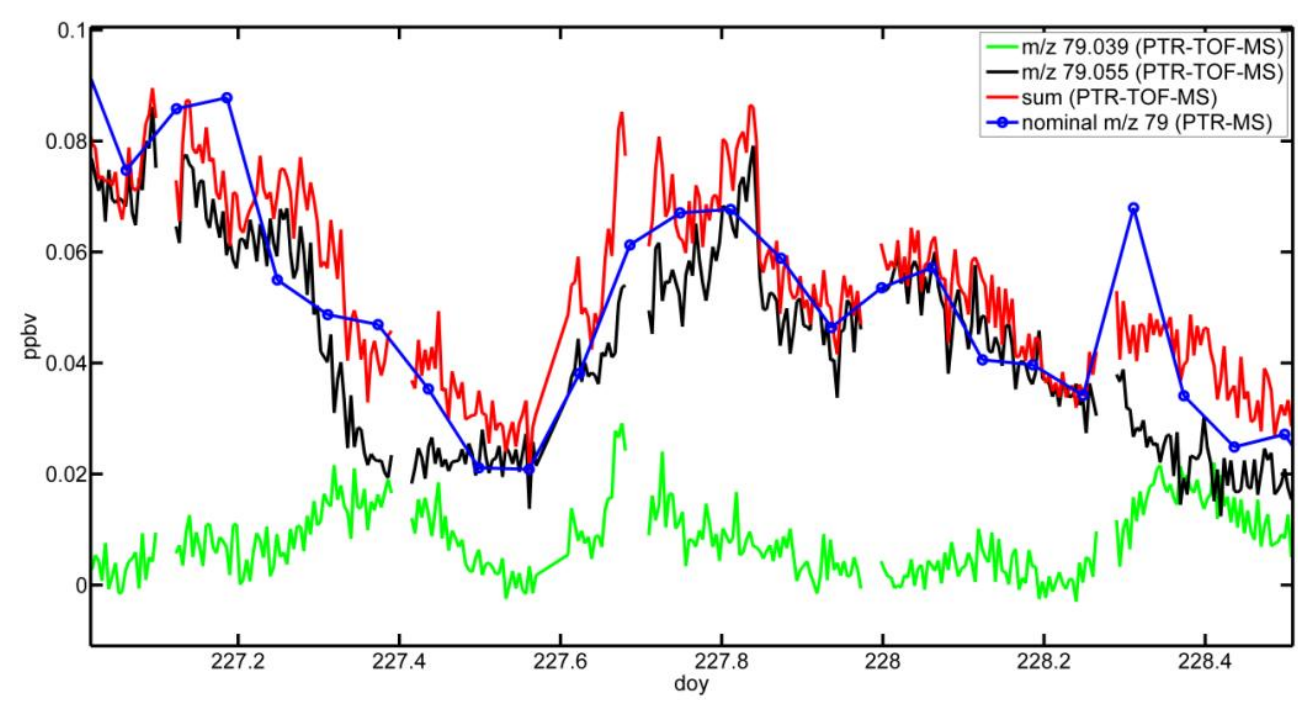

Fig. 4. Comparison between benzene measurements from PTR-MS at the nominal $\mathrm{m} / \mathrm{z}, 79$ (blue) and the sum (red) of the two relevant peaks found at the $m / z, 79.039 \mathrm{C}_{2} \mathrm{O}_{3} \mathrm{H}_{6}-\mathrm{H}^{+}$(green) and $m / z, 79.055 \mathrm{C}_{6} \mathrm{H}_{6}-\mathrm{H}^{+}$(black) by PTR-TOF-MS.

(5\%), $\mathrm{m} / \mathrm{z} 137.134(40 \%), \mathrm{m} / \mathrm{z} 95.0881(3 \%), \mathrm{m} / \mathrm{z} 93.0762$ $(<1 \%), \mathrm{m} / \mathrm{z} 81.0706(45 \%)$ and $\mathrm{m} / \mathrm{z} 69.0704(7 \%)$. Only two of the monoterpenes observed by TOGA were calibrated directly. The remaining monoterpenes were estimated based on known fragmentation patterns. It is therefore likely that the majority of the difference between the mixing ratio for the sum of monoterpenes reported by the PTR-(TOF)-MS systems and TOGA are due to the uncertainties in the calibration factors used for the remaining monoterpenes of TOGA. From Table 2, the R-values for the regressions ( 0.97 and 0.90 for comparisons of TOGA against PTR-TOF-MS and PTRMS, respectively) indicate that the precision of monoterpene data reported by TOGA is quite good, and thus additional speciated monoterpene calibrations would no doubt lead to overall better absolute mixing ratios.

Methanol was measured at $\mathrm{m} / \mathrm{z} 33(.0335)$, with mixing ratios typically between 1 and 13 ppbv. The PTR-MS, PTRTOF-MS and TOGA are in good agreement exhibiting regression slopes close to 1 and $R$ values better than 0.92 .

Acetaldehyde $[\mathrm{m} / \mathrm{z}, 45(.0335)]$ mixing ratios ranged between 0.25 and $3.5 \mathrm{ppbv}$. All instruments agreed to within $\pm 13 \%$.

Acetone $[\mathrm{m} / \mathrm{z}$ 59(.0491)] cannot be distinguished from its isomer propanal using PTR-(TOF)-MS. Therefore we compare PTR-(TOF)-MS data to the sum of acetone and propanal measured by TOGA. Based on these data, propanal typically contributed less than $5 \%$ to the PTR-MS signals on $\mathrm{m} / \mathrm{z}$ 59(.0491). The mixing ratios of the sum of acetone and propanal varied between 1 and 5 ppbv. All instruments agree well, with deviations from the 1:1 line of $\pm 17 \%$.

Acetonitrile $[\mathrm{m} / \mathrm{z}, 42(.0338)]$ mixing ratios during the comparison period were low with typical levels between 50 and 250 pptv. The small variation in ambient mixing ratio makes a direct regression analysis challenging. Therefore regression was forced through zero, which resulted in slopes close to one. All instruments agree to better than $\pm 11 \%$.

Methyl vinyl ketone $(M V K)$ and methacrolein $(M A C)$ are isomers that cannot be separated by PTR-(TOF)-MS. Both compounds are detected at $m / z$ 71(.0491). Typical mixing ratios for MVK plus MAC ranged between 50 and 700 pptv. Here only a comparison between the PTR-TOF-MS and TOGA is available since the PTR-MS did not measure $\mathrm{m} / \mathrm{z}$ 71. Compared to TOGA, the sum of MVK and MAC measured by PTR-TOF-MS is overestimated by $37 \%$ by the PTR-TOF-MS. 2-hydroxy-2-methylpropanal (HMPR) is reported as one of the major MBO OH oxidation products (Alvarado et al., 1999; Chan et al., 2009) and is expected to produce an ionic fragment at $\mathrm{m} / \mathrm{z}$ 71(.0491), which causes an interference with MVK and MAC. HMPR has a similar structure as MBO and it is very likely that PTR-MS instruments produce not only protonated HMPR but also the ionic fragment (water loss) at $\mathrm{m} / \mathrm{z}$ 71(.0491). The fragmentation pattern of HMPR from calibration in the lab indicates that the signal at $m / z 71(.0491)$ that is coming from HMPR at this site is in the range of $15 \%$. This is corroborated by our findings that $\mathrm{MBO}$ is much more abundant at this site than isoprene and the fact that HMPR is exclusively produced during the oxidation of MBO.

Methyl ethyl ketone (MEK) and butanal are both detected at $\mathrm{m} / \mathrm{z}$ 73(.0648), therefore we again compare the sum of both. Again only measurements from TOGA and PTR-TOFMS are available for this comparison. Mixing ratios ranged between 50 and 600 pptv. TOGA measurements indicated that daytime is dominated by butanal and nighttime by MEK. The instruments agree within $\pm 12 \%$. 
Benzene $(\mathrm{m} / \mathrm{z}, 79(.055))$ mixing ratios during the measurement campaign were quite low, between 10 and 200 pptv. PTR-TOF-MS, PTR-MS and TOGA measurements agree very well with slopes close to one. Figure 4 shows an additional interesting finding that the PTR-TOF-MS detected two significant peaks at $\mathrm{m} / z, 79.039\left(\mathrm{C}_{2} \mathrm{O}_{3} \mathrm{H}_{6}-\mathrm{H}^{+}\right)$ and $m / z 79.055\left(\mathrm{C}_{6} \mathrm{H}_{6}-\mathrm{H}^{+}\right.$protonated benzene) which are automatically summed up using the PTR-MS measuring at nominal resolution $\mathrm{m} / \mathrm{z}, 79$. At very low mixing ratios the compound at $\mathrm{m} / \mathrm{z} 79.039$ influences the ability of PTR-MS to accurately measure benzene mixing ratios. But the overall measurement agreement is not influenced. This peak on $\mathrm{m} / \mathrm{z} 79.039$ is likely due to the protonated acetic acid water cluster or the protonated glycolaldehyde water cluster. No other mass measured by PTR-MS during this field campaign was influenced in such a manner by isobaric species, based on observation using the PTR-TOF-MS.

Toluene is detected at $\mathrm{m} / \mathrm{z}$ 93(.0699) by PTR-MS and was present at mixing ratios between 10 and $250 \mathrm{pptv}$. The PTRTOF-MS detected a signal at $\mathrm{m} / \mathrm{z}$ 135.117, which follows the typical diurnal emission pattern of monoterpenes. This signal was attributed to the emission of cymene. Ambrose et al. (2010) suggest a possible interference from cymene on the toluene signal in ambient air above an alfalfa plantation surrounded by a hardwood/pine forest. From the literature (Tani et al., 2004) it is known that at an $E / N$ of $124 \mathrm{Td}$ the fraction of the cymene signal found at the interfering mass of toluene $\mathrm{m} / \mathrm{z}, 93.0699$ is not at all strongly dependent on humidity. It varies from 0.67 at $98 \% \mathrm{RH}$ to 0.71 at $28 \% \mathrm{RH}$. After recalibration of the fragmentation pattern of cymene in the laboratory at $60 \% \mathrm{RH}$, which lies in between the two values of Tani et al. (2004) we used the measured $\mathrm{m} / \mathrm{z} 135.117$ signal to correct the $m / z, 93.0699$ signal measured in ambient air at BEACHON-ROCS. The comparison between TOGA and PTR-TOF-MS using the uncorrected $\mathrm{m} / z 93.0669$ signal is poor with a slope of 0.72 . After correcting for the influence of cymene on $\mathrm{m} / \mathrm{z} 93.0699$ a regression slope of 0.98 was achieved. This correction could not be applied to the PTR-MS dataset since $\mathrm{m} / \mathrm{z}, 135$ was not monitored. Therefore we give in Table 2 both comparisons for the uncorrected as well as the corrected mixing ratios of toluene derived by the $\mathrm{m} / \mathrm{z}$ 93(.0699) signal. The comparison for $\mathrm{m} / \mathrm{z} 93$ however shows good agreement between PTR-TOF-MS and PTR-MS. The comparison between $\mathrm{m} / \mathrm{z}, 93$ and toluene indicates a similar cymene fragmentation pattern on the PTR-MS instrument, which would lead to a $26 \%$ bias on $\mathrm{m} / \mathrm{z} 93$, if it is solely attributed to toluene.

Peroxyacetyl nitrate (PAN) undergoes proton transfer with $\mathrm{H}_{3} \mathrm{O}^{+}$ions resulting in a signal at protonated PAN $\mathrm{m} / \mathrm{z} 122.008$ as well as fragment ions at $\mathrm{m} / \mathrm{z} 43.018$ and $\mathrm{m} / \mathrm{z} 45.993$ Protonated PAN reacts further with water to form a product ion $\mathrm{CH}_{3} \mathrm{C}(\mathrm{O}) \mathrm{OOHH}^{+}$with $m / z$ 77.0238. The realtime detection of PAN with PTR-MS systems is in detail described by (Hansel and Wisthaler, 2000). PAN was calibrated once during this field study for PTR-TOF-MS and frequently for the PAN-CIMS. The $m / z$ 77.0238, the major ion from PAN, was used to calculate PAN mixing ratios using PTR-TOF-MS data. The overall correlation between the PTR-TOF-MS and the PAN-CIMS is good with a correlation coefficient of 0.89 . The absolute mixing ratios of PAN vary between $150 \mathrm{pptv}$ and $1.5 \mathrm{ppbv}$. The PTR-TOF-MS system seems to overestimate PAN by $27 \%$, which could be due to another possible interference at $\mathrm{m} / \mathrm{z} 77.0238$ like protonated peroxyacetic acid.

Formaldehyde sensitivity in PTR-(TOF)-MS systems is highly water dependent due to the small difference in proton affinity between water and formaldehyde. The sensitivity therefore changes with the water content in sampled air. This water dependency was described by (Hansel et al., 1998; Vlasenko et al., 2010) and was confirmed here based on water dependent calibrations. Water sensitivity analyses of FILIF resulted in no detectable water interference (DiGangi, 2012). After accounting for the water dependent sensitivity of PTR-TOF-MS, formaldehyde mixing ratios differ by a factor of 2 with the PTR-TOF-MS measurements being higher than the FILIF. In contrast, the overall correlation between the two instruments is good with an $R$ of 0.85 . The largest uncertainty lies in the fact that both instruments were calibrated using different methods and the two methods were never cross calibrated. For both instruments a large inaccuracy in the range of $30-50 \%$ is given. The influence of ${ }^{15} \mathrm{NO}^{+}$interfering with protonated formaldehyde $\left(\mathrm{CHOHH}^{+}\right)$in PTR-TOF-MS can be ruled out as TOF-MS allows separation of these two ions. The higher signal of PTR-TOF-MS compared to FILIF can also not be explained by interferences of the ion generated by $\mathrm{O}_{2}^{+}$reacting with methanol as the instrument was operated at a low $\mathrm{O}_{2}^{+} \mathrm{impu}-$ rity of about $1 \%$. PTR-TOF-MS measurements give an upper limit of formaldehyde as the signal could be influenced by an ion overlapping formaldehyde at $\mathrm{m} / \mathrm{z}$ 31.0177. A possible candidate for this could be a fragment ion of protonated methyl hydroperoxide.

\section{Conclusions}

This comparison of five different on-line VOC measurements during the BEACHON ROCS field campaign in 2010 gives a realistic picture of the current ability to quantify the dominant VOC species above a natural ponderosa pine environment. Comparisons of methanol, the sum of MBO and isoprene, acetaldehyde, the sum of acetone and propanal, benzene and the sum of MEK and butanal and the sum of monoterpenes show good agreement. At this site where $\mathrm{MBO}$ and monoterpene emissions are dominating it is important to note that PTR-(TOF)-MS instruments have interferences. HMPR a photooxidation product of MBO produces a fragment ion that interferes with the sum of MVK and MAC. The same is true for cymene that interferes with toluene. However, we demonstrate how these interferences 
can be corrected leading to better agreement. PAN measured by PAN-CIMS and PTR-TOF-MS generally agrees within $27 \%$. It remains unclear whether this difference results from calibration differences (i.e. the PTR-TOF-MS was only calibrated once during the study) or an interfering species like peroxyacetic acid in the PTR-TOF-MS instrument. Formaldehyde measured by FILIF and PTR-TOF-MS differs by a factor of 2 , which can only be explained by calibration problems or an interference in the PTR-TOF-MS e.g. methylhydroperoxide resulting in a signal at $\mathrm{m} / z$ 31.0177. The amount of isoprene/(isoprene + MBO) could not satisfactory be resolved at this site. The GC instruments (TOGA and whole air samples) detect on average $25 \%$. In contrast PTR-(TOF)-MS instruments detect only $5 \%$.

Our results demonstrate that a combination of different VOC measurement techniques help to constrain the uncertainty of VOC measurements. This is especially important to accurately assess the photo oxidative capacity of the atmosphere. For example $\mathrm{OH}$ reactivity measurements rely heavily on an accurate assessment of ambient VOC mixing ratios. Missing sources of $\mathrm{OH}$ reactivity (e.g. in form of unmeasured BVOCs) have been reported to be on the order of $20-50 \%$ (Di Carlo et al., 2004). The excellent agreement of measured $[\mathrm{OH}]$ and modeled $[\mathrm{OH}]$ during this study (Kim et al., 2013) underlines the importance of this VOC comparison.

Acknowledgements. We thank the whole BEACHON-ROCS field campaign team for helpful discussions. This work was financially supported by the Austrian Science Fund (FWF) under the project number L518-N20. The National Center for Atmospheric Research is operated by the University Corporation for Atmospheric Research under sponsorship from the National Science Foundation. Lisa Kaser is a recipient of a DOC-fFORTE-fellowship of the Austrian Academy of Science. Martin Graus received support from a United States Department of Agriculture project (USDA 2009-35112-05217) granted to Carsten Warneke and Ray Fall. FILIF measurements were supported by the National Science Foundation (ATM 0852406). The authors would also like to thank David Gochis for providing precipitation data measured during the field campaign.

Edited by: R. Holzinger

\section{References}

Alvarado, A., Tuazon, E. C., Aschmann, S. M., Arey, J., and Atkinson, R.: Products and mechanisms of the gas-phase reactions of $\mathrm{OH}$ radicals and O-3 with 2-methyl-3-buten-2-ol, Atmos. Environ., 33, 2893-2905, 1999.

Ambrose, J. L., Haase, K., Russo, R. S., Zhou, Y., White, M. L., Frinak, E. K., Jordan, C., Mayne, H. R., Talbot, R., and Sive, B. C.: A comparison of GC-FID and PTR-MS toluene measurements in ambient air under conditions of enhanced monoterpene loading, Atmos. Meas. Tech., 3, 959-980, doi:10.5194/amt-3959-2010, 2010.
Apel, E. C., Riemer, D. D., Hills, A., Baugh, W., Orlando, J., Faloona, I., Tan, D., Brune, W., Lamb, B., Westberg, H., Carroll, M. A., Thornberry, T., and Geron, C.: Measurement and interpretation of isoprene fluxes, and isoprene, methacrolein, and methyl vinyl ketone mixing ratios at the PROPHET site during the 1998 Intensive, J. Geophys. Res., 107, 4034, doi:10.1029/2000JD000225, 2002.

Apel, E. C., Hills, A. J., Lueb, R., Zindel, S., Eisele, S., and Riemer, D. D.: A fast-GC/MS system to measure C-2 to C-4 carbonyls and methanol aboard aircraft, J. Geophys. Res., 108, 8794, doi:10.1029/2002JD003199, 2003.

Apel, E. C., Brauers, T., Koppmann, R., Bandowe, B., Bossmeyer, J., Holzke, C., Tillmann, R., Wahner, A., Wegener, R., Brunner, A., Jocher, M., Ruuskanen, T., Spirig, C., Steigner, D., Steinbrecher, R., Alvarez, E. G., Muller, K., Burrows, J. P., Schade, G., Solomon, S. J., Ladstatter-Weissenmayer, A., Simmonds, P., Young, D., Hopkins, J. R., Lewis, A. C., Legreid, G., Reimann, S., Hansel, A., Wisthaler, A., Blake, R. S., Ellis, A. M., Monks, P. S., and Wyche, K. P.: Intercomparison of oxygenated volatile organic compound measurements at the SAPHIR atmosphere simulation chamber, J. Geophys. Res.-Atmos., 113, D20307, doi:10.1029/2008jd009865, 2008.

Apel, E. C., Emmons, L. K., Karl, T., Flocke, F., Hills, A. J., Madronich, S., Lee-Taylor, J., Fried, A., Weibring, P., Walega, J., Richter, D., Tie, X., Mauldin, L., Campos, T., Weinheimer, A., Knapp, D., Sive, B., Kleinman, L., Springston, S., Zaveri, R., Ortega, J., Voss, P., Blake, D., Baker, A., Warneke, C., Welsh-Bon, D., de Gouw, J., Zheng, J., Zhang, R., Rudolph, J., Junkermann, W., and Riemer, D. D.: Chemical evolution of volatile organic compounds in the outflow of the Mexico City Metropolitan area, Atmos. Chem. Phys., 10, 2353-2375, doi:10.5194/acp-10-23532010, 2010.

Atkinson, R.: Atmospheric chemistry of VOCs and $\mathrm{NO}_{\mathrm{x}}$, Atmos. Environ., 34, 2063-2101, 2000.

Carrasco, N., Doussin, J. F., O’Connor, M., Wenger, J. C. PicquetVarrault, B., Durand-Jolibois, R., and Carlier, P.: Simulation chamber studies of the atmospheric oxidation of 2-methyl-3buten-2-ol: Reaction with hydroxyl radicals and ozone under a variety of conditions, J. Atmos. Chem., 56, 33-55, 2007.

Chan, A. W. H., Galloway, M. M., Kwan, A. J., Chhabra, P. S., Keutsch, F. N., Wennberg, P. O., Flagan, R. C., and Seinfeld, J. H.: Photooxidation of 2-Methyl-3-Buten-2-ol (MBO) as a Potential Source of Secondary Organic Aerosol, Environ. Sci. Technol., 43, 4647-4652, doi:10.1021/Es802560w, 2009.

Di Carlo, P., Brune, W. H., Martinez, M., Harder, H., Lesher, R., Ren, X. R., Thornberry, T., Carroll, M. A., Young, V., Shepson, P. B., Riemer, D., Apel, E., and Campbell, C.: Missing OH reactivity in a forest: Evidence for unknown reactive biogenic VOCs, Science, 304, 722-725, 2004.

DiGangi, J. P.: Formaldehyde as a Probe of Rural Volatile Organic Compound Oxidation, Ph.D. thesis, University of Wisconsin, Madison, USA, 2012.

DiGangi, J. P., Boyle, E. S., Karl, T., Harley, P., Turnipseed, A., Kim, S., Cantrell, C., Maudlin, R. L., Zheng, W., Flocke, F., Hall, S. R., Ullmann, K., Nakashima, Y., Paul, J. B., Wolfe, G. M., Desai, A. R., Kajii, Y., Guenther, A., and Keutsch, F. N.: First direct measurements of formaldehyde flux via eddy covariance: implications for missing in-canopy formaldehyde sources, Atmos. Chem. Phys., 11, 10565-10578, doi:10.5194/acp-11- 
10565-2011, 2011

Fall, R., Karl, T., Jordon, A., and Lindinger, W.: Biogenic C5VOCs: release from leaves after freeze-thaw wounding and occurrence in air at a high mountain observatory, Atmos. Environ., 35, 39053916, 2001.

Fortner, E. C., Zheng, J., Zhang, R., Berk Knighton, W., Volkamer, R. M., Sheehy, P., Molina, L., and André, M.: Measurements of Volatile Organic Compounds Using Proton Transfer Reaction - Mass Spectrometry during the MILAGRO 2006 Campaign, Atmos. Chem. Phys., 9, 467-481, doi:10.5194/acp-9-467-2009, 2009.

Fry, J. L., Draper, D. C., Zarzana, K. J., Campuzano-Jost, P., Day, D. A., Jimenez, J. L., Brown, S. S., Cohen, R. C., Kaser, L., Hansel, A., Cappellin, L., Karl, T., Hodzic Roux, A., Turnipseed, A., Cantrell, C., Lefer, B. L., and Grossberg, N.: Observations of gas- and aerosol-phase organic nitrates at BEACHONRoMBAS 2011, Atmos. Chem. Phys. Discuss., 13, 1979-2034, doi:10.5194/acpd-13-1979-2013, 2013.

Goldstein, A. H., McKay, M., Kurpius, M. R., Schade, G. W., Lee, A., Holzinger, R., and Rasmussen, R. A.: Forest thinning experiment confirms ozone deposition to forest canopy is dominated by reaction with biogenic VOCs, Geophys. Res. Lett., 31, L22106, doi:10.1029/2004g1021259, 2004.

Graus, M., Müller, M., and Hansel, A.: High Resolution PTRTOF: Quantification and Formula Confirmation of VOC in Real Time, J. Am. Soc. Mass. Spectrom., 21, 1037-1044, doi:10.1016/j.jasms.2010.02.006, 2010

Hallquist, M., Wenger, J. C., Baltensperger, U., Rudich, Y., Simpson, D., Claeys, M., Dommen, J., Donahue, N. M., George, C., Goldstein, A. H., Hamilton, J. F., Herrmann, H., Hoffmann, T., Iinuma, Y., Jang, M., Jenkin, M. E., Jimenez, J. L., Kiendler-Scharr, A., Maenhaut, W., McFiggans, G., Mentel, Th. F., Monod, A., Prévôt, A. S. H., Seinfeld, J. H., Surratt, J. D., Szmigielski, R., and Wildt, J.: The formation, properties and impact of secondary organic aerosol: current and emerging issues, Atmos. Chem. Phys., 9, 5155-5236, doi:10.5194/acp-95155-2009, 2009.

Hansel, A. and Wisthaler, A.: A method for real-time detection of PAN, PPN and MPAN in ambient air, Geophys. Res. Lett., 27, 895-898, 2000.

Hansel, A., Jordan, A., Holzinger, R., Prazeller, P., Vogel, W., and Lindinger, W.: Proton-Transfer Reaction Mass-Spectrometry Online Trace Gas-Analysis at the Ppb Level, Int. J. Mass Spectrom., 149, 609-619, 1995.

Hansel, A., Wisthaler, A., Schwarzmann, M., and Lindinger,W.: Energy dependencies of the proton transfer reactions $\mathrm{H}_{3} \mathrm{O}^{+}+\mathrm{CH}_{2} \mathrm{O}<->\mathrm{CH}_{2} \mathrm{OH}^{+}+\mathrm{H}_{2} \mathrm{O}$, Int. J. Mass Spectrom. Ion Proc., 167/168, 697-703, 1998.

Harley, P., Fridd-Stroud, V., Greenberg, J., Guenther, A. and Vasconcellos, P.: Emission of 2-methyl-3-buten-2-ol by pines: A potentially large natural source of reactive carbon to the atmosphere, J. Geophys. Res.-Atmos., 103, 25479-25486, 1998.

Helsel, D. R. and Hirsch, R. M.: Statistical Methods in Water Resources, New York, NY, USA, Elsevier, 1993.

Hornbrook, R. S., Blake, D. R., Diskin, G. S., Fried, A., Fuelberg, H. E., Meinardi, S., Mikoviny, T., Richter, D., Sachse, G. W., Vay, S. A., Walega, J., Weibring, P., Weinheimer, A. J., Wiedinmyer, C., Wisthaler, A., Hills, A., Riemer, D. D., and Apel, E. C.: Observations of nonmethane organic compounds during ARC-
TAS - Part 1: Biomass burning emissions and plume enhancements, Atmos. Chem. Phys., 11, 11103-11130, doi:10.5194/acp11-11103-2011, 2011.

Jordan, A., Haidacher, S., Hanel, G., Hartungen, E., Mark, L., Seehauser, H., Schottkowsky, R., Sulzer, P., and Mark, T. D.: A high resolution and high sensitivity proton-transfer-reaction time-offlight mass spectrometer (PTR-TOF-MS), Int. J. Mass. Spectrom., 286, 122-128, doi:10.1016/j.ijms.2009.07.005, 2009.

Karl, T., Apel, E., Hodzic, A., Riemer, D. D., Blake, D. R., and Wiedinmyer, C.: Emissions of volatile organic compounds inferred from airborne flux measurements over a megacity, Atmos. Chem. Phys., 9, 271-285, doi:10.5194/acp-9-271-2009, 2009.

Karl, T., Hansel, A., Cappellin, L., Kaser, L., Herdlinger-Blatt, I., and Jud, W.: Selective measurements of isoprene and 2methyl-3-buten-2-ol based on $\mathrm{NO}^{+}$ionization mass spectrometry, Atmos. Chem. Phys., 12, 11877-11884, doi:10.5194/acp12-11877-2012, 2012.

Kim, S., Karl, T., Guenther, A., Tyndall, G., Orlando, J., Harley, P., Rasmussen, R., and Apel, E.: Emissions and ambient distributions of Biogenic Volatile Organic Compounds (BVOC) in a ponderosa pine ecosystem: interpretation of PTR-MS mass spectra, Atmos. Chem. Phys., 10, 1759-1771, doi:10.5194/acp-101759-2010, 2010.

Kim, S., Wolfe, G. M., Mauldin, L., Cantrell, C., Guenther, A., Karl, T., Turnipseed, A., Greenberg, J., Hall, S. R., Ullmann, K., Apel, E., Hornbrook, R., Kajii, Y., Nakashima, Y., Keutsch, F. N., DiGangi, J. P., Henry, S. B., Kaser, L., Schnitzhofer, R., Graus, M., Hansel, A., Zheng, W., and Flocke, F. F.: Evaluation of HOx sources and cycling using measurement-constrained model calculations in a 2-methyl-3-butene-2-ol (MBO) and monoterpene (MT) dominated ecosystem, Atmos. Chem. Phys., 13, 20312044, doi:10.5194/acp-13-2031-2013, 2013.

Kleb, M. M., Chen, G., Crawford, J. H., Flocke, F. M., and Brown, C. C.: An overview of measurement comparisons from the INTEX-B/MILAGRO airborne field campaign, Atmos. Meas. Tech., 4, 9-27, doi:10.5194/amt-4-9-2011, 2011.

Kuster, W. C., Jobson, B. T., Karl, T., Riemer, D., Apel, E., Goldan, P. D., and Fehsenfeld, F. C.: Intercomparison of volatile organic carbon measurement techniques and data at la porte during the TexAQS2000 Air Quality Study, Environ. Sci. Technol., 38, 221228, doi:10.1021/Es034710r, 2004.

Lindinger, W., Hansel, A., and Jordan, A.: On-line monitoring of volatile organic compounds at pptv levels by means of protontransfer-reaction mass spectrometry (PTR-MS) - Medical applications, food control and environmental research, Int. J. Mass Spectrom., 173, 191-241, 1998.

Liu, Y. J., Herdlinger-Blatt, I., McKinney, K. A., and Martin, S. T.: Production of methyl vinyl ketone and methacrolein via the hydroperoxyl pathway of isoprene oxidation, Atmos. Chem. Phys. Discuss., 12, 33323-33358, doi:10.5194/acpd-12-33323-2012, 2012.

Montzka, S. A., Trainer, M., Goldan, P. D., Kuster, W. C., and Fehsenfeld, F. C.: Isoprene and Its Oxidation-Products, Methyl Vinyl Ketone and Methacrolein, in the Rural Troposphere, J. Geophys. Res.-Atmos., 98, 1101-1111, 1993.

Müller, M., Graus, M., Ruuskanen, T. M., Schnitzhofer, R., Bamberger, I., Kaser, L., Titzmann, T., Hörtnagl, L., Wohlfahrt, G., Karl, T., and Hansel, A.: First eddy covariance flux measurements by PTR-TOF, Atmos. Meas. Tech., 3, 387-395, 
doi:10.5194/amt-3-387-2010, 2010.

Russo, R. S., Zhou, Y., White, M. L., Mao, H., Talbot, R., and Sive, B. C.: Multi-year (2004-2008) record of nonmethane hydrocarbons and halocarbons in New England: seasonal variations and regional sources, Atmos. Chem. Phys., 10, 4909-4929, doi:10.5194/acp-10-4909-2010, 2010.

Slusher, D. L., Huey, L. G., Tanner, D. J., Flocke, F. M., and Roberts, J. M.: A thermal dissociation-chemical ionization mass spectrometry (TD-CIMS) technique for the simultaneous measurement of peroxyacyl nitrates and dinitrogen pentoxide, J. Geophys. Res.-Atmos., 109, D19315, doi:10.1029/2004jd004670, 2004.

Tani, A., Hayward, S., Hansel, A., and Hewitt, C. N.: Effect of water vapour pressure on monoterpene measurements using proton transfer reaction-mass spectrometry (PTR-MS), Int. J. Mass Spectrom., 239, 161-169, doi:10.1016/j.ijms.2004.07.020, 2004.

Vlasenko, A., Macdonald, A. M., Sjostedt, S. J., and Abbatt, J. P. D.: Formaldehyde measurements by Proton transfer reaction - Mass Spectrometry (PTR-MS): correction for humidity effects, Atmos. Meas. Tech., 3, 1055-1062, doi:10.5194/amt-3-1055-2010, 2010.

Warneke, C., Veres, P., Holloway, J. S., Stutz, J., Tsai, C., Alvarez, S., Rappenglueck, B., Fehsenfeld, F. C., Graus, M., Gilman, J. B., and de Gouw, J. A.: Airborne formaldehyde measurements using PTR-MS: calibration, humidity dependence, intercomparison and initial results, Atmos. Meas. Tech., 4, 23452358, doi:10.5194/amt-4-2345-2011, 2011.
Zhang, R. Y., Suh, I., Lei, W., Clinkenbeard, A. D., and North, S. W.: Kinetic studies of OH-initiated reactions of isoprene, J. Geophys. Res.-Atmos., 105, 24627-24635, 2000.

Zhao, J. and Zhang, R.: Proton transfer reaction rate constants between hydronium ion $\left(\mathrm{H}_{3} \mathrm{O}^{+}\right)$and volatile organic compounds, Atmos. Environ., 38, 2177-2185, 2004.

Zheng, W., Flocke, F. M., Tyndall, G. S., Swanson, A., Orlando, J. J., Roberts, J. M., Huey, L. G., and Tanner, D. J.: Characterization of a thermal decomposition chemical ionization mass spectrometer for the measurement of peroxy acyl nitrates (PANs) in the atmosphere, Atmos. Chem. Phys., 11, 6529-6547, doi:10.5194/acp-11-6529-2011, 2011.

Zhou, Y., Mao, H., Russo, R. S., Blake, D. R., Wingenter, O. W., Haase, K. B., Ambrose, J., Varner, R. K., Talbot, R., and Sive, B. C.: Bromoform and dibromomethane measurements in the seacoast region of New Hampshire, 2002-2004, J. Geophys. Res., 113, D08305, doi:10.1029/2007JD009103, 2008. 